\title{
The choice of optimal antireflux procedure after laparoscopic cardiomyotomy: two decades of clinical experience in one center
}

\author{
Mindaugas Kiudelis ${ }^{1}$, Egle Kubiliute ${ }^{1}$, Egidijus Sakalys ${ }^{1}$, Laimas Jonaitis ${ }^{2}$, Antanas Mickevicius ${ }^{1}$, Zilvinas Endzinas ${ }^{1}$ \\ ${ }^{1}$ Clinic of Surgery, Lithuanian University of Health Sciences, Kaunas, Lithuania \\ ${ }^{2}$ Clinic of Gastroenterology, Lithuanian University of Health Sciences, Kaunas, Lithuania
}

Videosurgery Miniinv 2017; 12 (3): 238-244

DOI: https://doi.org/10.5114/wiitm.2017.68547

\begin{abstract}
Introduction: Two types of partial wrap are commonly performed in achalasia patients after Heller myotomy: the posterior $270^{\circ}$ fundoplication (Toupet) and the anterior $180^{\circ}$ fundoplication (Dor). The optimal type of fundoplication (posterior vs. anterior) is still debated.

Aim: To compare the long-term rates of dysphagia, reflux symptoms and patient satisfaction with current postoperative condition between two fundoplication groups in achalasia treatment.

Material and methods: Our retrospective study included 97 consecutive patients with achalasia: 37 patients underwent laparoscopic posterior Toupet (270 ) fundoplication followed by Heller myotomy (group I); 60 patients underwent laparoscopic anterior partial Dor fundoplication followed by Heller myotomy (group II). Long-term follow-up results included evaluation of dysphagia symptoms, intensity of heartburn and patient satisfaction with current condition.

Results: Patients in these two groups did not differ according to age, weight, height, postoperative stay or follow-up period. Laparoscopic myotomy with posterior Toupet fundoplication was effective in $89 \%$ of patients, while laparoscopic myotomy with anterior Dor was effective in $93 \%$ of patients $(p>0.05) .11 \%$ of patients after posterior Toupet fundoplication had clinically significant heartburn vs. $35 \%$ of patients after anterior Dor fundoplication $(p<0.05)$. Overall patient satisfaction with current condition was $88 \%$, with no significant difference between the groups.

Conclusions: According to our study results, the two laparoscopic techniques were similarly effective in reducing achalasia symptoms, but postoperative clinical manifestation of heartburn is significantly more frequent after anterior Dor fundoplication (35\% vs. 11\%). The majority of patients (88\%) were satisfied with operation outcomes.
\end{abstract}

Key words: fundoplication, achalasia, laparoscopic Heller myotomy.

\section{Introduction}

Achalasia is characterized by aperistalsis of the esophageal body and poor relaxation of the lower esophageal sphincter (LES). Clinical manifestations of the disease include dysphagia, regurgitation, heartburn, and chest pain. Laparoscopic Heller cardiomyotomy (LHC) is now a standard surgical procedure for achalasia treatment. It has been shown to reduce dysphagia symptoms and improve quality of life $[1,2]$.

Esophageal myotomy performed alone induces gastroesophageal reflux in a large percentage of patients because of interruption of the LES mechanism [3]. Persistent dysphagia and postoperative gastroesophageal reflux (GER) are the most frequent indicators of surgical treatment failure. Csendes et al. [4]

\section{Address for correspondence}

Egle Kubiliute, Clinic of Surgery, Hospital of Lithuanian University of Health Sciences, Kaunas Clinics, 2 Eiveniu St, 50161 Kaunas,

Lithuania, phone: +37 069592518, e-mail: egle.kubiliute@gmail.com 
found that poor outcomes 15.8 years after myotomy were related to severe reflux disease and were not associated with incomplete myotomy in $92 \%$ of patients. Since 2012 SAGES has strongly recommended that patients who undergo esophageal myotomy should also have a fundoplication to prevent postoperative reflux and minimize treatment failures [5]. To date, two types of partial wrap are commonly performed in achalasia patients after Heller myotomy: the posterior $270^{\circ}$ fundoplication (Toupet) and the anterior $180^{\circ}$ fundoplication (Dor). Each of these procedures has advantages and disadvantages, but the optimal type of fundoplication (posterior vs. anterior) is still debated. There is a clear need for additional evidence in order to determine which partial fundoplication provides the best reflux control after myotomy.

\section{Aim}

The aim of our present study was to compare the long-term rates of dysphagia, reflux symptoms and patient satisfaction after surgery and current postoperative condition between Toupet and Dor fundoplication groups in achalasia treatment.

\section{Material and methods}

We performed a retrospective study, which included 97 consecutive patients with achalasia. Patients were treated between January 1998 and December 2016 in the clinic of surgery of Kaunas Medical University Hospital. All the patients gave their written informed consent, and the Regional Biomedical Research Ethics Committee approved the study (No. BEC-LSMU(R)-40).

Patients with clinical symptoms of achalasia were examined by a surgeon or gastroenterologist at the appointment in the outpatient clinic. After radiological examination with barium contrast, esophagogastroduodenoscopy (EGD) and manometric studies, achalasia was diagnosed. Diagnosis of achalasia was confirmed by manometric analysis in all of the patients: elevated resting lower esophageal sphincter (LES) pressure (> $45 \mathrm{~mm} \mathrm{Hg}$ ); incomplete LES relaxation after a swallow; and peristalsis in the smooth muscle portion of the body of the esophagus. When the diagnosis was confirmed, all achalasia treatment options, their benefits and risks were explained to the patients in detail. The main attention was paid to the patient's general condi- tion, co-morbidities, previous intra-abdominal operations and the patient's choice. The final decision was made by consensus agreement.

All patients were divided into two groups according to the fundoplication procedure performed after cardiomyotomy. The first group (37 patients) underwent laparoscopic posterior Toupet $\left(270^{\circ}\right)$ fundoplication followed by Heller myotomy. The second group (60 patients) underwent laparoscopic anterior partial Dor fundoplication followed by Heller myotomy. Three experienced surgeons performed all the operations. The fundoplication technique was chosen independently by the operating surgeon except the cases where mucosa perforation during cardiomyotomy occurred. The mucosa was sutured, and anterior Dor fundoplication was performed in all of these cases (these 5 patients were also included in the Dor group analysis).

Postoperative follow-up included length of in-hospital stay, early dysphagia, and intraoperative and postoperative complications rate. A careful clinical assessment was performed by questionnaire in each patient before and late after surgery. The results of achalasia treatment were divided into four classes according to Vantrappen and Hellemans [6] (Table I). Heartburn grade was evaluated according to the standard grading system (Table II).

Excellent (0) and good (I) results were considered as indicative of successful achalasia treatment, while moderate (II) and poor (III) were considered as treatment failure. Clinically significant heartburn was considered when the heartburn grade was II or III.

Table I. Classes on the effectiveness of achalasia treatment (according to Vantrappen and Hellemans)

\begin{tabular}{|lc|}
\hline Classes & Dysphagia \\
\hline Excellent (0) & Completely free of symptoms \\
\hline Good (I) & $\begin{array}{c}\text { Occasional (less than once a week) dys- } \\
\text { phagia or pain of short duration defined as } \\
\text { retrosternal hesitation of food lasting from } \\
\text { 2-3 s to 2-3 min and disappearing after } \\
\text { drinking fluids }\end{array}$ \\
\hline Moderate (II) & $\begin{array}{c}\text { Dysphagia more than once a week lasting } \\
\text { less than 2-3 min and not accompanied by } \\
\text { regurgitation or weight loss }\end{array}$ \\
\hline Poor (III) & $\begin{array}{c}\text { Dysphagia more than once a week or last- } \\
\text { ing 2-3 min or longer or accompanied by } \\
\text { regurgitation or weight loss }\end{array}$ \\
\hline
\end{tabular}


Table II. Heartburn standard grading system

\begin{tabular}{|c|c|}
\hline Grade & Heartburn \\
\hline 0 & None \\
\hline । & $\begin{array}{l}\text { Minimal - episodic; no treatment is } \\
\text { required }\end{array}$ \\
\hline II & Moderate - controlled with medication \\
\hline III & $\begin{array}{l}\text { Severe - interferes with daily activity or not } \\
\text { controlled with medication }\end{array}$ \\
\hline
\end{tabular}

\section{Operative techniques}

\section{Myotomy and posterior Toupet fundoplication}

The esophageal hiatus was fully dissected mobilizing the esophagus circumferentially, separating from mediastinal structures and crura, followed by full mobilization of the gastric fundus. This included division of the phrenoesophageal membrane and gastrophrenic and gastrosplenic ligaments with short gastric vessels. Any epiphrenic fat pad was removed and myotomy performed using an ultrasonic hook $6-8 \mathrm{~cm}$ in length on the anterior surface of the esophagus. The myotomy extends $1.5-2 \mathrm{~cm}$ beyond the gastro-esophageal junction. Then posterior Toupet $\left(270^{\circ}\right)$ fundoplication was performed: the leading edge of the fundus was positioned to the right of the esophagus and sutured to the right side of the opened muscle over a length of $3 \mathrm{~cm}$; the anterior fundus was fixed to the left side of the opened muscle over a length of $3 \mathrm{~cm}$; finally the wrap was secured to the right and left crura with separate gastrocrural sutures.

\section{Myotomy and posterior Dor fundoplication}

Anterior limited dissection of the esophageal hiatus was performed: separating the esophagus from the mediastinal structures and crura, with clear identification of the anterior vagal nerve, but leaving the lateral and posterior phrenoesophageal attachments intact. The short gastric vessels were not divided. The fat pad from the anterior esophagus was removed. The myotomy was performed in the same manner. Anterior Dor fundoplication was performed: the left anterior fundus was fixed to the left side of the myotomy and the left crus of the diaphragm; the leading edge of the fundus was positioned along the greater curvature, anterior to the esophagus over the myotomy and sutured to the right side of the myotomy and the right crus of the diaphragm.

\section{Statistical analysis}

Fisher's exact test was used to compare the success and complications of different treatment modalities. The patients' age, history of the disease, hospital stay and follow-up period between the groups were compared using the unpaired Mann-Whitney $U$ test. $P$-value $<0.05$ was considered significant.

\section{Results}

From January 1998 to December 2016, 97 consecutive patients with achalasia were treated: 37 underwent Heller myotomy plus posterior Toupet fundoplication (group I) and 60 underwent Heller myotomy plus anterior Dor fundoplication (group II). Patients' general characteristics are summarized in Table III.

Heller myotomy with Toupet or Dor fundoplication was the initial treatment in all 97 patients and they had no achalasia treatment before. All the procedures were performed laparoscopically without conversions. Perioperative follow-up results are summarized in Table IV. One patient from the Dor fundoplication group had esophageal mucosa leak, detected on the second postoperative day after taking semi-liquid food. This patient underwent re-laparoscopy, primary closure of the perforation site and drainage. The postoperative period was uneventful.

Follow-up was available to all 97 operated patients. Eighty-seven (88\%) patients evaluated their current condition as excellent or good with no significant difference between the groups, while only 12 (12\%) patients rated the outcome as satisfactory. Patient satisfaction with surgery outcome scores are presented in Table V.

Dysphagia symptoms decreased dramatically after surgery. Laparoscopic myotomy with posterior Toupet fundoplication was effective in $89 \%$ of patients (good and excellent results) at long-term follow-up, while laparoscopic myotomy with anterior Dor fundoplication gave the same good or excellent outcome in $93 \%$ of patients $(p>0.05)$.

A significant difference between the two groups was found in heartburn scores. Thirty-five percent of patients after myotomy with anterior Dor fundoplication had clinically significant heartburn (grade II-III), but only $11 \%$ of patients after myotomy with 
Table III. Patient general characteristics

\begin{tabular}{|c|c|c|c|}
\hline Parameter & Group I (Toupet) $(n=37)$ & $\begin{array}{c}\text { Group II (Dor) }(n=60) \\
\text { Median (min.-max.) }\end{array}$ & $P$-value \\
\hline Age [year] & $53.2(19-76)$ & $46.7(18-82)$ & NS \\
\hline \multicolumn{4}{|l|}{ Gender: } \\
\hline Male & $23(62)$ & $38(63)$ & NS \\
\hline Female & $14(38)$ & $22(37)$ & NS \\
\hline History of achalasia [months] & $40.1(3-240)$ & $41.7(6-259)$ & NS \\
\hline Follow-up [months] & $102.7(6-221)$ & $98.8(12-223)$ & NS \\
\hline ASA score & $1.9(1-3)$ & $1.8(1-3)$ & NS \\
\hline \multicolumn{4}{|c|}{ Dysphagia before treatment (classes): } \\
\hline 1 & $1(2.7)$ & $3(5)$ & NS \\
\hline$\|$ & $6(16.2)$ & $8(13.3)$ & NS \\
\hline III & 30 (81.1) & 49 (81.7) & NS \\
\hline Heartburn before treatment & $3(8.1)$ & $5(8.3)$ & NS \\
\hline
\end{tabular}

Results presented as median (min.-max.) or n (\%).

Table IV. Perioperative follow-up results

\begin{tabular}{|lccc|}
\hline Parameter & Group I (Toupet) $(n=37)$ & Group II (Dor) $(n=60)$ & $P$-value \\
\hline Hospital stay [days] & $4.1(2-7)$ & $4.5(2-9)$ & NS \\
\hline Operating time [min] & $102.1(60-135)$ & $108.7(50-165)$ & NS \\
\hline Mucosal perforation during operation & $5(13.5)$ & 0 & NS \\
\hline Postoperative complications & 0 & $1(1.7)$ & NS \\
\hline Early dysphagia (in-hospital) & 0 & 0 & NS \\
\hline
\end{tabular}

Results presented as median (min.-max.) or $n(\%)$.

Table V. Patient's evaluation of current postoperative condition

\begin{tabular}{|lcc|}
\hline Parameter & Group I (Toupet) $(n=37)$ & Group II (Dor) $(n=60)$ \\
\hline Excellent & $28(76 \%)$ & $38(63 \%)$ \\
\hline Good & $5(13 \%)$ & $14(23 \%)$ \\
\hline Satisfactory & $4(11 \%)$ & $8(14 \%)$ \\
\hline Poor & 0 & 0 \\
\hline
\end{tabular}

posterior Toupet fundoplication $(p<0.05)$. Achalasia treatment results are presented in Table VI.

\section{Discussion}

Over the past 17 years the high success rate of laparoscopic Heller myotomy for achalasia has brought a shift in practice; surgery has become the preferred treatment of most gastroenterologists and other referring physicians [7]. Nowadays, laparoscopic Heller myotomy is routinely considered as an option for achalasia patients. Discussion about advantages and disadvantages of fundoplication after Heller myotomy has been going on for many years. Some authors have reported rather low rates of GER (11.3\% global rate after a long-term follow-up) after 
Table VI. Achalasia treatment results

\begin{tabular}{|lccc|}
\hline Parameter & Group I (Toupet) $(n=37)$ & Group II (Dor) $(n=60)$ & $P$-value \\
\hline Dysphagia classes (\%): & $15(40.5 \%)$ & $26(43.3 \%)$ & NS \\
\hline \hline II & $18(48.6 \%)$ & $30(50 \%)$ & NS \\
\hline Heartburn grade (\%): & $4(10.9 \%)$ & $4(6.7 \%)$ & NS \\
\hline 0 & $25(67.6 \%)$ & $24(40 \%)$ & $<0.05$ \\
\hline I & $8(21.6 \%)$ & $15(25 \%)$ & NS \\
\hline III & $4(10.8 \%)$ & $19(31.7 \%)$ & $<0.05$ \\
\hline
\end{tabular}

laparoscopic myotomy alone [8]. Lyass et al. [9] in their meta-analysis also found that the difference in the rate of GER diagnosed in post-myotomy $\mathrm{pH}$ studies in wrapped and non-wrapped patients was not significant (7.9 vs. $10 \%$, respectively; $p=0.75)$. There was also no significant difference in the incidence of post-myotomy GER symptoms in wrapped and nonwrapped patients ( 5.9 vs. $13 \%$ respectively; $p=0.12$ ).

It is worth pointing out that many studies have demonstrated a high incidence of GER when physiologic testing is performed in no antireflux procedure groups: Campos et al. [1] in a systematic review and meta-analysis reported the rate of $41.5 \%$ for abnormal reflux when no fundoplication was added compared with $14.5 \%$ when one was performed ( $p=0.01)$; Falkenback et al. [10] in their prospective randomized trial found that postoperative reflux was observed in $100 \%$ of the patients who had the myotomy alone vs. $25 \%$ of those who had myotomy with Nissen fundoplication; Richards et al. [3] in their prospective randomized trial found that $48 \%$ of patients in the myotomy-alone group had abnormal GER postoperatively, while only $9 \%$ of patients had abnormal pH studies when myotomy and partial Dor fundoplication were performed. According to the published results, the routine application of fundoplication following laparoscopic Heller myotomy has been recommended as beneficial for protection against postoperative GER $[1,11]$. The type of fundoplication has been a subject of debate until now. An anterior $180^{\circ}$ Dor fundoplication, a posterior $270^{\circ}$ Toupet fundoplication, and a loose Nissen fundoplication have all been proposed. Nissen fundoplica- tion is usually considered as a contraindication in patients with achalasia because of the underlying esophageal aperistalsis. Rebecchi et al. [12] in a randomized, controlled trial compared the incidence of GER and the rate of dysphagia between Nissen and Dor fundoplication groups, following laparoscopic Heller myotomy. They observed that Dor fundoplication was equally as effective as "floppy" Nissen fundoplication in controlling reflux, but dysphagia rates were significantly higher in the Nissen group $(2.8 \%$ vs. $15 \%$, respectively; $p<0.001$ ). Therefore, a partial fundoplication following laparoscopic Heller myotomy is generally preferred nowadays.

Both partial fundoplications (Dor and Toupet) accompanied by laparoscopic Heller myotomy are associated with improvement or resolution of dysphagia symptoms. Campos et al. [1] in their metaanalysis reported symptom improvement in $89.3 \%$ of achalasia patients. Rawlings et al. [13] in a randomized controlled trial reported improvement of dysphagia symptoms after laparoscopic Heller myotomy in $90.9 \%$ in the Dor group and $93.1 \%$ in the Toupet group at 6-month to 12-month follow-up. Our study results also demonstrate that resolution of dysphagia symptoms or their improvement was achieved in $89 \%$ in the Toupet group and $93 \%$ in the Dor group at long-term follow up with a median of 98.8 months to 102.7 months. Our data correspond to the results published in previous studies.

The main function of the antireflux procedure after myotomy is to prevent GER, because gastroesophageal reflux is commonly regarded as one of the main failures of surgical treatment. 
The goal of our retrospective study was to find out which partial fundoplication better controls GER after Heller myotomy. Rawlings et al. [13] in a randomized controlled trial found that the rate of pathologic acid reflux as measured by $24-\mathrm{h} \mathrm{pH}$ testing was twice as high in the Dor group compared with the Toupet group (41.7\% vs. $21.1 \%)$. This difference did not reach statistical significance only because of the small sample size. Wei et al. [11] performed a meta-analysis in which they compared Dor fundoplication with non-fundoplication surgery or other types of fundoplication surgery for achalasia. This meta-analysis identified a significantly higher recurrence rate of clinical regurgitation and pathological acid reflux for Dor fundoplication than for other types of fundoplication after laparoscopic myotomy for achalasia. No significant difference was found between Dor fundoplication and no fundoplication. They concluded that Dor fundoplication after laparoscopic myotomy is not the optimal procedure for achalasia. Our study results are similar to the results published in the meta-analysis: $11 \%$ patients had clinically significant heartburn after myotomy with Toupet fundoplication versus 35\% after myotomy with anterior Dor fundoplication after a median 99-month follow-up. We fully support the point of view that such results can be explained by the fact that Dor fundoplication may add less resistance than Toupet fundoplication, which allows acid to flow through the loose esophagogastric junction more easily.

One of the operation efficiency indicators is patient satisfaction with surgery results and current condition. Tomasko et al. [14] found that overall satisfaction with laparoscopic myotomy + fundoplication results and current postoperative condition was $89 \%$ for all patients ( $88 \%$ Toupet vs. $93 \%$ Dor). Our study obtained similar results: overall patient satisfaction with current postoperative condition and well-being was $88 \%$ (evaluated as excellent or good), with no significant difference between the groups (89\% Toupet vs. $86 \%$ Dor).

There are some serious limitations to this study: (1) This is a retrospective study but not a randomized clinical trial where the fundoplication technique was chosen independently by the operating surgeon; (2) preoperative and postoperative acid reflux were assessed only in clinical terms by questionnaire using the standard heartburn grading system, but not by $24-\mathrm{h} \mathrm{pH}$ testing, which is the generally accepted objective pathologic GER testing method.

\section{Conclusions}

According to our study results, the two laparoscopic techniques (myotomy + Toupet or Dor) were similarly effective ( $89 \%$ vs. $93 \%$ ) in reducing achalasia symptoms. Postoperative clinically significant heartburn is significantly more often present $35 \%$ vs. $11 \%$ ) after anterior Dor fundoplication followed by laparoscopic myotomy. Overall patient satisfaction with current postoperative condition was $88 \%$, with no significant difference between the groups.

Based on our results, we recommend laparoscopic posterior Toupet $270^{\circ}$ fundoplication followed by Heller myotomy for achalasia surgical treatment.

\section{Conflict of interest}

The authors declare no conflict of interest.

\section{References}

1. Campos G, Vittinghoff E, Rabl C, et al. Endoscopic and surgical treatments for achalasia: a systematic review and metaanalysis. Ann Surg 2009; 249: 45-57.

2. Ben-Meir A, Urbach DR, Khajanchee YS, et al. Quality of life before and after laparoscopic Heller myotomy for achalasia. Am J Surg 2001; 181: 471-4.

3. Richards WO, Torquati A, Holzman M, et al. Heller myotomy versus Heller myotomy with Dor fundoplication for achalasia: a prospective randomized double-blind clinical trial. Ann Surg 2004; 240: 405-15.

4. Csendes A, Braghetto I, Henriquez A, Cortes C. Late results of prospective randomized study comparing forceful dilatation and esophagomyotomy in patients with achalasia. Gut 1989; 30: 299-304.

5. SAGES guidelines for the surgical treatment of esophageal achalasia. Surg Endosc 2012; 26: 296-311.

6. Vantrappen G, Hellemans J. Treatment of achalasia and related motor disorders. Gastroenterology 1980; 79: 144-54.

7. Patti MG, Fisichella PM, Perretta $S$, et al. Impact of minimally invasive surgery on the treatment of esophageal achalasia: a decade of change. J Am Coll Surg 2003; 196: 698-703.

8. Robert M, Poncet G, Mion F, Boulez J. Results of laparoscopic Heller myotomy without anti-reflux procedure in achalasia. Monometric prospective study of 106 cases. Surg Endosc 2008; 22: 866-74.

9. Lyass S, Thoman D, Steiner JP, Phillips E. Current status of an antireflux procedure in laparoscopic Heller myotomy. Surg Endosc 2003; 17: 554-8.

10. Falkenback D, Johansson J, Oberg S, et al. Heller's esophagomyotomy with or without a $360^{\circ}$ degrees floppy Nissen fundoplication for achalasia. Long-term results from a prospective, randomized trial. Dis Esophagus 2003; 16: 284-90.

11. Wei MT, He YZ, Deng XB, et al. Is Dor fundoplication optimum after laparoscopic Heller myotomy for achalasia? A meta-analysis. World J Gastroenterol 2013; 19: 7804-12. 
12. Rebecchi F, Giaccone C, Farinella E, et al. Randomized controlled trial of laparoscopic Heller myotomy plus Dor fundoplication versus Nissen fundoplication for achalasia: long-term results. Ann Surg 2008; 248: 1023-30.

13. Rawlings A, Soper N, Oelschlager B, et al. Laparoscopic Dor versus Toupet fundoplication following Heller myotomy for achalasia: results of a multicenter, prospective randomized-controlled trial. Surg Endosc 2012; 26: 18-26.

14. Tomasko JM, Augustin T, Tran TT, et al. Quality of life comparing Dor and Toupet after Heller myotomy for achalasia. JSLS 2014; 18: e2014.00191.

Received: 10.03.2017, accepted: 21.05.2017. 